\title{
Polymeric Functionalized Stationary Phase for Separation of Ionic Compounds by IC
}

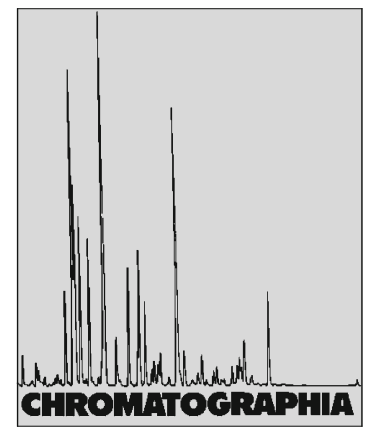

2010, 72, 611-616

\author{
Magdalena Jaćkowska, Szymon Bocian, Przemysław Kosobucki, Bogusław Buszewski ${ }^{\bowtie}$ \\ Faculty of Chemistry, Department of Environmental Chemistry and Bioanalytics, Nicolaus Copernicus University, \\ Gagarin 7, 87-100 Toruń, Poland; E-Mail: bbusz@chem.uni.torun.pl
}

\begin{abstract}
Synthesis and properties are described of multilayered stationary phases containing quaternary amine functional groups used for the analysis of inorganic anions by ion chromatography. The bonded phases were characterized by elemental analysis, solid state ${ }^{13} \mathrm{C} N \mathrm{MR}$ spectroscopy and chromatographic methods. The surface of polyhydroxyethyl methacrylate (solid support) was coated with polymeric layers formed by condensation polymerization of primary amine with diepoxide. Each layer of the anion exchange stationary phase consisted of methylamine and 1,4-butanedioldiglycidyl ether copolymer. A series of stationary phases with different number of polymerized layers were tested. Separation of inorganic anions, such as $\mathrm{F}^{-}, \mathrm{Cl}^{-}, \mathrm{NO}_{2}^{-}, \mathrm{Br}^{-}, \mathrm{NO}_{3}{ }^{-}$, were performed. Aqueous hydroxide, carbonate and bicarbonate solutions were used as mobile phases.
\end{abstract}

\section{Keywords}

Ion chromatography

Stationary phases

Inorganic anions

Separation selectivity

Quaternary ammonium groups

\section{Introduction}

For the last 20 years, ion chromatography (IC) has become a popular chromatographic technique for the determination of inorganic and organic ions [1-3]. IC provides good repeatability and a wide range of applications used for water quality control procedures [4-6], atmosphere monitoring [7], food analysis [8,9] and within the pharmaceutical industry [10]. Since the introduction of IC much research has been conducted in order to address ion-exchange selectivity and improvement of separation of anions, particularly in the development of sta- tionary phases. In recent years, the number of ion-exchange materials increased dynamically $[11,12]$.

The majority of stationary phases currently used for separation of ionic compounds are based on organic polymers and silica gel. In contrast to stationary phases prepared on silica gel, organic polymers show higher stability towards extreme $\mathrm{pH}$ conditions. The silica-based anion exchangers [13, 14] can be operated only in between $\mathrm{pH}$ 2.0-9.5 while polymeric ion exchangers are stable across the entire $\mathrm{pH}$ range. Thus, styrene/divinylbenzene (PS/DVB) copolymers [15, 16], polyvinyl and polymethacrylate resins [17] are the most important organic polymers used as materials in the manufacturing process for polymer-based anion exchangers.

As far as IC columns are concerned, a number of problems have to be taken into consideration when developing stationary phases. One important aspect deals with the analysis of samples with high concentrations which require high ion-exchange capacity. An increased column capacity is necessary in order to achieve suitable separations of more complex mixtures. This becomes also relevant in cases where sample analysis encounters huge disproportions of particular analyte concentrations (analytical and preparative scale). The improvement of column efficiency is an important 
feature during stationary phase development and involves a decrease in particle size as well as the surface chemistry [18]. The separation selectivity depends mostly on the stationary phase and the influence of the mobile phase is rather weak and one of the popular anionexchange groups are quaternary ammonium groups [19, 20].

The main aim of this study was the synthesis of a newly functionalized stationary phase containing quaternary ammonium groups used for ion chromatography. A novel anion-exchanger was prepared by chemical modification of the polymer support surface forming a Joshua Tree-like structure. Controlled synthesis allows for the formation of a defined number of bonded layers, hence leading to desirable properties in ionexchange capacity. Monomers such as 1.4-butanedioldiglycidyl ether (BDDE) and methylamine (MA) were used.

\section{Experimental}

\section{Instrumentation}

Chromatographic analyses were performed with an ion chromatograph Dionex model, ICS-3000 consisting of a pump, a degasser, an autosampler, a thermostat, a conductometric detector. Data collection and analysis was performed on a personal computer using the Chromeleon Chromatography Management 6.8. software (Dionex Corporation, Sunnyvale, USA). The Dionex Suppressor ASRS-ULTRA II 2-mm was installed between the analytical column and conductometric detector.

Solid-state ${ }^{13} \mathrm{C}$ NMR cross-polarization magic angle spinning (CP-MAS) measurements were recorded on a MSL 300 spectrometer (Bruker, Karlsruhe, Germany) at a resonance frequency of $4,500 \mathrm{~Hz}$, using a zirconium rotor $(7 \mathrm{~mm}$ diameter). All spectra were externally referenced with liquid tetramethylsilane (TMS) and the chemical shifts $(\delta)$ were given in parts per million (ppm). Elemental analysis was done using a PerkinElmer CHN 240 analyzer (Palo Alto, USA).

The porosity parameters characterizing the starting material were determined by low-temperature nitrogen adsorption-desorption method using a Model ASAR 2010 (version 2.0) sorptomatic apparatus (Micrometrics, Norcross, GA, USA).

A micrograph of the packing was obtained from a scanning electron microscope (SEM) type 1430 VP (LEO Electron Microscopy, England).

Water was purified with a Milli-Q Purification System (Millipore, Bedford, USA). The $\mathrm{pH}$ measurements of the mobile phase were performed with a pH meter CP-505 (Elmetron, Zabrze, Poland).

\section{Chemicals and Eluents}

The solid support of laboratory-prepared phases was polyhydroxyethyl methacrylate Spheron 300 (Lachema, Brno Czech Republic) with a particle diameter of 25-40 $\mu \mathrm{m}$. The properties of this polymer were presented earlier [16]. The following reagents were used for the chemical modification of the polymer support material. Methylamine (MA, $40 \%$ in $\left.\mathrm{H}_{2} \mathrm{O}, v / v\right)$ and 1.4-butanedioldiglycidyl ether (BDDE, 95\% in $\mathrm{H}_{2} \mathrm{O}, v / v$ ). Both reagents were obtained from SigmaAldrich Chemie (Steinheim, Germany).

Sodium fluoride, sodium chloride, sodium nitrite, potassium nitrate, potassium bromide, sodium carbonate and sodium hydrogen carbonate were of analytical grade and purchased from POCh (Gliwice, Poland).

\section{Preparation of the Anion-Exchanger}

Figure 1 shows the chemical structure of the anion-exchanger prepared in our laboratory.

The basic condensation polymerization chemistry depends on MA and BDDE as monomers to build a branching polymer that possess quaternary ammonium anion exchanger sites. This stationary phase was prepared using 25-40 $\mu \mathrm{m}$ polyhydroxyethyl methacrylate. The support sample (4 g) was wetted with $1 \%(v / v) \mathrm{HCl}$, then filtered and rinsed with redistilled water to obtain a neutral pH. A $15 \mathrm{~mL}$ mixture of mono- mers $\quad(2.6-3.0 \%$ MA and $7.0-7.4 \%$ BDDE) was added to the resin and reacted for $30 \mathrm{~min}$ at a temperature of $60-70{ }^{\circ} \mathrm{C}$. After reaction the mixture was filtered and rinsed with redistilled water. Following the addition of $15 \mathrm{~mL}$ $3.0-5.0 \%(v / v)$ MA was added to the resin and reacted for $30 \mathrm{~min}$ at a temperature $60-70{ }^{\circ} \mathrm{C}$, filtered and rinsed with redistilled water. Next $15 \mathrm{~mL}$ $9.0-11.0 \%(v / v)$ was added to the resin and reacted for $30 \mathrm{~min}$ at a temperature $60-70{ }^{\circ} \mathrm{C}$, filtered and rinsed with redistilled water. The last two steps were repeated three, seven, eleven and fifteen times to make 3, 7, 11 and 15-layers on solid support, respectively.

\section{Results and Discussion}

\section{Physico-Chemical Characterizations of the Stationary Phases}

The new anion exchanger that may be used as a stationary phase for the determination of ionic compounds was subjected to a variety of physico-chemical characterization procedures. These included elemental analysis (CHN), nuclear magnetic resonance spectroscopy $\left({ }^{13} \mathrm{C}\right.$ CP-MAS NMR) and chromatographic methods. The $\mathrm{CHN}$ analysis was performed for the pure polymer and after modification with 3, 7, 11 and 15 bonded polymer layers. To control the number of layers polymerized on solid support the nitrogen content (percentage) was chosen as the main parameter. The percentage values obtained were $0.14,0.40,0.91$ and $1.35(\% \mathrm{~N})$ for 3,7 , 11 and 15 polymer bonded layers in the stationary phase, respectively. As it can be expected, the percentage of the nitrogen in the stationary phases increased exponentially with the number of bonded layers. Non-linear increase of the nitrogen content may suggest that the number of nitrogen atoms found in successive layers was higher than in the previous one and this observation agreed well with a Joshua Tree model of the synthesized stationary phase. This correlation can be useful for the control of bonded layer numbers formed during stationary phase preparation. In this 
case the elemental analysis data was invaluable in confirming the identity of the polymeric resins structure for anionexchange chromatography.

A ${ }^{13} \mathrm{C}$ CP-MAS NMR spectrum of Spheron 300 before and after modification is presented in Fig. 2.

The interpretation of these spectra was difficult because the amount of added carbon is relatively low in comparison to the carbon content present in the support. Additionally, some of the functional groups are present in support and bonded phase. In the support, the presence of methyl groups gave a signal at $\delta=+55.1 \mathrm{ppm}$ and methylene carbons connected with oxygen $\left(-\mathrm{O}-\mathrm{CH}_{2}-\right.$ ) were observed at $\delta=+66.4 \mathrm{ppm}$. Signals at $\delta=+17.8 \mathrm{ppm}$ and $\delta=+177.2 \mathrm{ppm}$ corresponded to the presence of methyl and carbonyl groups, respectively. A quaternary carbon atom gave a signal at $\delta=+45.2 \mathrm{ppm}$. After the modification a new signal was observed at $\delta=+25.8$ ppm that corresponded to a methylene groups as a result of carbon chain formation. Signals in the range between $\delta=+71.3-75.4 \mathrm{ppm}$ corresponded to methylene groups connected with oxygen $\left(-\mathrm{O}-\mathrm{CH}_{2}\right)$, nitrogen $\left(-\mathrm{CH}_{2}-\mathrm{N}-\right)$ and carbon connected to an ether bond and hydroxyl group. The signals intensity at $\delta=+55.1, \delta=+60.2 \mathrm{ppm}$ decrease significantly after modification of the support.

\section{Chromatographic Characterization of the Stationary Phases}

All synthesized stationary phases containing 3, 7, 11 and 15 bonded layers were tested using five representative inorganic anions. The composition of tested mixture included fluoride, chloride, nitrite, bromide and nitrate anions at a concentration of $20 \mathrm{mg} \mathrm{L}^{-1}$. The column void volume was obtained from the solvent peak. Inorganic anions were separated with the hydroxyethyl methacrylate-based anion-exchange column using four different eluents consisting of aqueous hydroxide, carbonate, bicarbonate and bicarbonate-carbonate solutions as the mobile phase. A variety of changes in mobile phase compositions

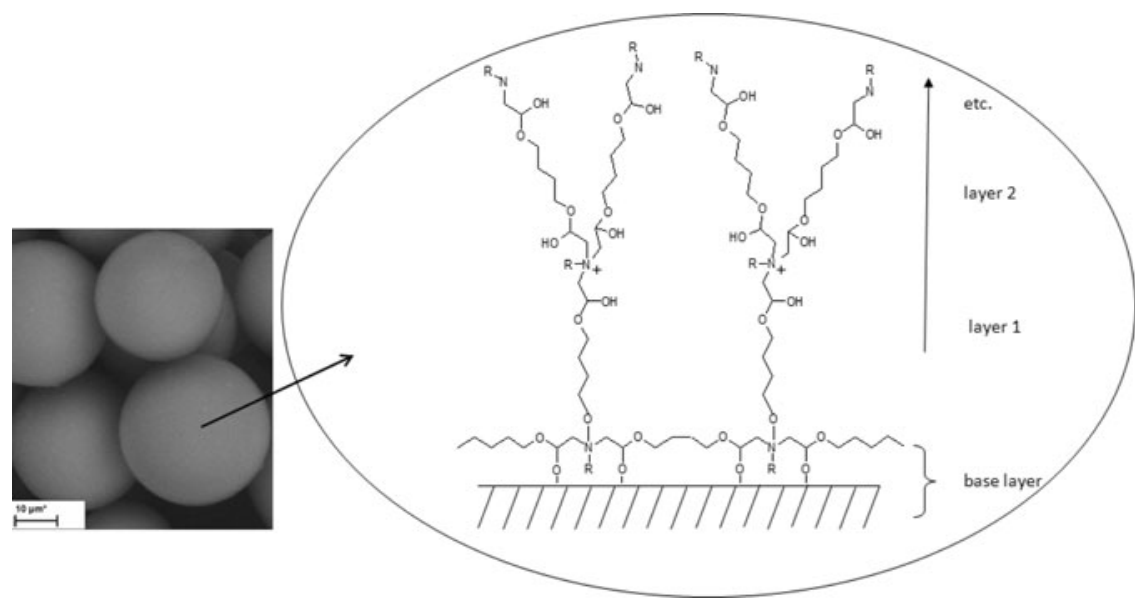

Fig. 1. Structure of the stationary phase

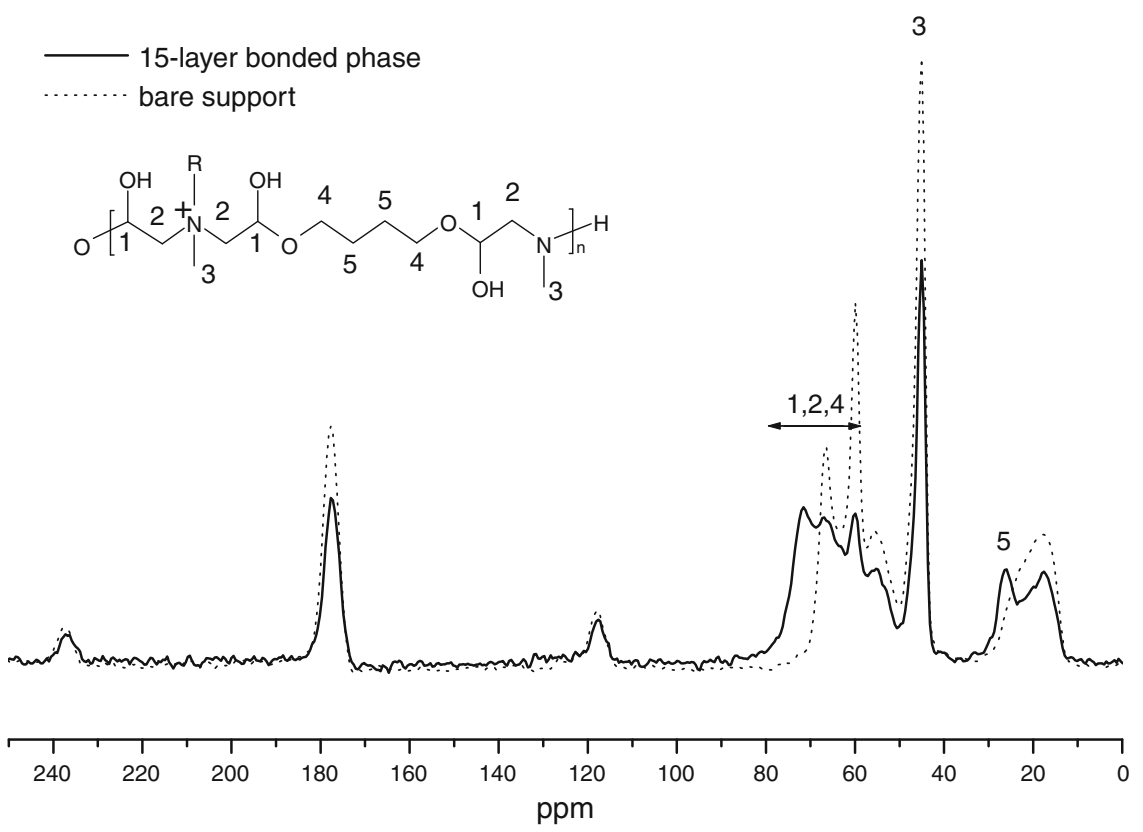

Fig. 2. ${ }^{13} \mathrm{C}$ CP-MAS NMR spectra of Spheron 300 before and after modification (15 layers). $R$ represents another branch of the Joshua Tree

were evaluated for the impact on separation and modification of $\mathrm{pH}(\mathrm{pH}$ 8.21 for $\mathrm{NaHCO}_{3}, 11.76$ for $\left.\mathrm{NaOH}\right)$. Representative chromatograms using the 7-, 11-, 15-layered stationary phase using bicarbonate-carbonate solutions are shown in Fig. 3.

Under these conditions we obtained a separation of five inorganic anions with resolution $\left(R_{S}\right)$ values ranging from 1.41 to 0.96 . Asymmetry factors $\left(f_{A S}\right)$ of the peaks presented in the chromatogram ranged from 0.84 to 1.63 . Table 1 sum- marizes retention, peak asymmetry $\left(f_{A S}\right)$ and resolution $\left(R_{s}\right)$ characteristics of the three tested columns.

A carbonate/bicarbonate buffer was used as the mobile phase. Since the stationary phases were synthesized on the polymer with a wide range of particle diameter retention is presented as $k^{\prime} / S_{B E T}$ where retention factor $\left(k^{\prime}\right)$ was divided by the specific surface area of the polymer support $\left[S_{B E T}\right.$, specfic surface measured by BET method $\left.\left(\mathrm{m}^{2} \mathrm{~g}^{-1}\right)\right]$. The order of the elution was independent of the number of 


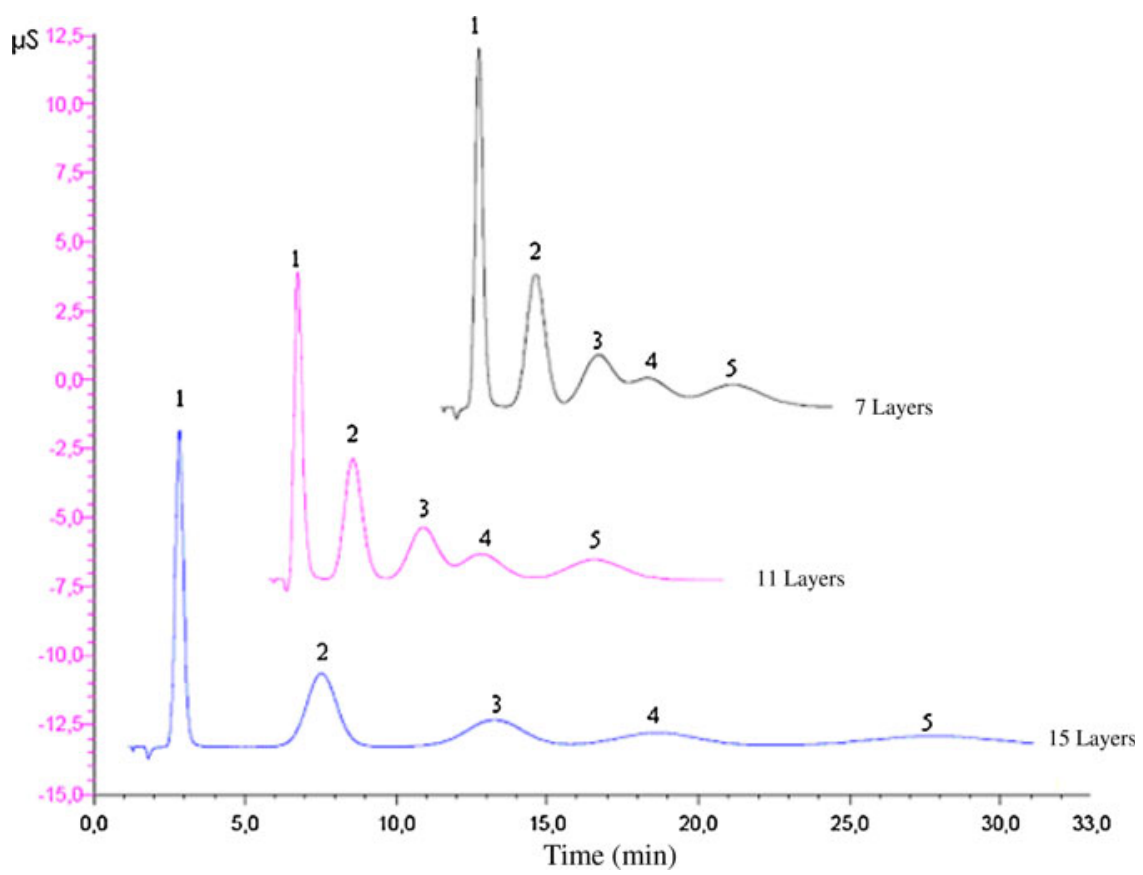

Fig. 3. Separation of inorganic anions on hydroxyethyl methacrylate based column: $250 \times 2.1 \mathrm{~mm} ; 7,11$ and 15 layers of MA-BDDE; flow-rate: $1.2 \mathrm{~mL} \mathrm{~min}{ }^{-1}$; detection: suppressed conductivity. Eluent: $2.2 \mathrm{mM} \mathrm{Na} \mathrm{CO}_{3}+2.8 \mathrm{mM} \mathrm{NaHCO} 3$ (pH 9.71). Peaks: $\mathbf{1}=$ fluoride; $\mathbf{2}=$ chloride; $\mathbf{3}=$ nitrite; $\mathbf{4}=$ bromide; $\mathbf{5}=$ nitrate

Table 1. Comparison of the resolution $\left(R_{S}\right)$ and peak asymmetry factor $\left(f_{A S}\right)$ on the 7-, 11- and 15-layers bonded phase

\begin{tabular}{|c|c|c|c|c|c|c|c|c|c|}
\hline \multirow[t]{3}{*}{ Solute } & \multicolumn{9}{|c|}{ Number of layers } \\
\hline & \multicolumn{3}{|l|}{$n=7$} & \multicolumn{3}{|c|}{$n=11$} & \multicolumn{3}{|c|}{$n=15$} \\
\hline & $k^{\prime}$ & $R_{S}$ & $f_{A S}$ & $k^{\prime}$ & $R_{S}$ & $f_{A S}$ & $k^{\prime}$ & $R_{S}$ & $f_{A S}$ \\
\hline $\mathrm{F}^{-}$ & 1.31 & & 1.19 & 1.58 & & 1.10 & 0.68 & & 1.49 \\
\hline $\mathrm{Cl}^{-}$ & 4.56 & 2.51 & 1.11 & 8.67 & 2.51 & 1.07 & 3.88 & 2.15 & 1.21 \\
\hline $\mathrm{NO}_{2}^{-}$ & 8.12 & 1.51 & 1.07 & 17.34 & 2.23 & 1.06 & 8.06 & 1.60 & 1.09 \\
\hline $\mathrm{Br}^{-}$ & 11.02 & 0.99 & 0.85 & 25.67 & 1.58 & 1.01 & 11.55 & 0.93 & 1.17 \\
\hline $\mathrm{NO}_{3}^{-}$ & 16.06 & 1.39 & 1.06 & 39.49 & 1.45 & 0.86 & 18.15 & 1.33 & 1.13 \\
\hline
\end{tabular}

Table 2. Anion exchange capacity factors of anions, $k^{\prime}=\frac{t_{r}-t_{0}}{t_{0}}$ with various mobile phases

\begin{tabular}{|llllll|}
\hline Solute & \multirow{2}{*}{$\begin{array}{l}\text { Concentration } \\
\left(\mathrm{mg}^{-1} \mathrm{~L}\right)\end{array}$} & \multicolumn{4}{l}{$k^{\prime}$} \\
\cline { 3 - 6 } & & $\begin{array}{l}2.5 \mathrm{mM} \\
\mathrm{NaOH}\end{array}$ & $2.0 \mathrm{mM}$ & $8.0 \mathrm{mM}$ & $2.2 \mathrm{mM}$ \\
& & & & & $\mathrm{Na}_{2} \mathrm{CO}_{3}$ \\
& & $\mathrm{NaHCO}_{3}$ & $\begin{array}{l}\mathrm{Na}_{2} \mathrm{CO}_{3}+2.8 \mathrm{mM} \\
\mathrm{NaHCO}_{3}\end{array}$ \\
\hline Fluoride & 20.24 & 1.05 & 0.68 & 1.29 & 0.68 \\
Chloride & 20.10 & 3.81 & 3.70 & 6.83 & 3.88 \\
Nitrite & 20.09 & 6.60 & 7.40 & 13.75 & 8.06 \\
Bromie & 20.24 & 8.89 & 10.42 & 19.69 & 11.55 \\
Nitrate & 19.80 & 13.12 & 16.26 & 30.57 & 18.15 \\
\hline
\end{tabular}

bonded layers in the stationary phase. All synthesized stationary phases allowed for the formation of symmetrical peaks for all tested anions. Asymmetry factors ranged between 0.85 and 1.49 .
Table 2 shows the changes of the retention of five anions using different buffers such as aqueous hydroxide, bicarbonate, carbonate and bicarbonate/ carbonate solutions as a mobile phase.
The order of anion elution was independent of the used buffer. Anions exhibited the highest retention when bicarbonate buffer was used as a mobile phase and the lowest retention was observed using sodium hydroxide solution. The retention of tested anions decreased with increased mobile phase $\mathrm{pH}$. On the tested stationary phase sodium hydroxide had the highest elution strength (and highest $\mathrm{pH}$ ). It is contradictory to the commonly knowledge, where the sodium hydroxide is considered as a rather weak eluent [17].

Using all tested eluents, anions exhibited high $k^{\prime}$ values resulting in excellent selectivity for all used compounds. Despite the relatively low retention of the first fluoride peak it was also well separated from the solvent peak at the beginning of the chromatogram.

Figure 4 displays the changes of retention $\left(k^{\prime}\right)$ versus mobile phase $\mathrm{pH}$ observed for the 15-layered bonded phase.

A mixture of carbonate/bicarbonate buffer $(2.2 \mathrm{mM} / 2.8 \mathrm{mM})$ was used as the mobile phase. The highest decrease in retention factor was observed with increased mobile phase $\mathrm{pH}$ from 9.0 to 9.5. In the $\mathrm{pH}$ range 9.5-10.5 the retention factor was almost constant. However, a slight decrease was observed, especially for highly retained nitrate anions. Application of the eluent with $\mathrm{pH}<9$ lead to significantly increased retention which was not desirable.

As expected, the retention factor of all anions strongly depended on the number of bonded layers (Fig. 5).

The stationary phase containing only three layers did not exhibit any retention under measurements conditions. The increase of the retention from 7 to 15 bonded layers was connected with the increase of the quaternary ammonium groups number present in the structure of the bonded phase. The higher number of ion-exchange centers in the stationary phase lead to increased ion retention. According to the Joshua Tree model of the stationary phases, the number of quaternary ammonium groups changed exponentially with the number of bonded layers. The retention factor of all anions changed in a similar manner over the number of bonded layers. 
The selectivity of the separations was compared using different mobile phase $\mathrm{pH}$ values for carbonate/bicarbonate eluents and using different buffers (hydroxide, carbonate, bicarbonate and mixture carbonate/bicarbonate). Data obtained for the 15 layers are presented in Figs. $6 a$ and b, respectively.

The highest selectivity $(\alpha)$ was observed for first pair (fluoride/chloride). The lowest selectivity was observed for nitrite/bromide and bromide/nitrate anions. However, the selectivity of all ions was above $1.1 \quad\left(\log _{\alpha}>0.5\right)$. Figure 6a revealed that when a carbonate/bicarbonate buffer was used selectivity was almost independent from the mobile phase $\mathrm{pH}$.

Selectivity did not depend on the quantitative composition of the buffer. For four tested buffers, selectivity was not observed to change more than $10 \%$ which suggested that selectivity depended mostly on the stationary phase rather than the mobile phase. Selectivity was not significantly affected by the number of bonded layers.

\section{Conclusions}

The preparation of newly functionalized stationary phases used for ion chromatography is presented. A polymeric resin containing quaternary ammonium functional groups is a suitable material for ion chromatographic separations of inorganic anions. A series of bonded phases which contained more than three bonded layers exhibited high retention and selectivity. The retention of all anions increased with the number of bonded layers which was associated with increased adsorption centers present in the stationary phase. On the other hand selectivity was independent of the mobile phase $\mathrm{pH}$ and used buffer. Synthesized stationary phases may be successfully applied to the determination of inorganic anions found in environmental samples such as mineral and spring water. Optimal conditions included the use of a 15layered bonded phase and a mobile phase of $2.2 \mathrm{mM} \mathrm{Na} \mathrm{CO}_{3}+2.8 \mathrm{mM}$ $\mathrm{NaHCO}_{3}(\mathrm{pH}=9.71)$.

\section{Acknowledgments}

This work was sponsored by the European Social Found, Polish National Budget, Kujawsko-pomorskie Voivodship Budget (within Sectoral Operational Programme Human Resources) - "Stypendia dla doktorantów 2008/2009ZPORR".

\section{Open Access}

This article is distributed under the terms of the Creative Commons Attribution Noncommercial License which permits any noncommercial use, distribution, and reproduction in any medium, provided the original author(s) and source are credited.

\section{References}

1. Small H, Stevens TS, Bauman WS (1975) Anal Chem 47:1801-1809. doi:10.1021/ ac60361a017

2. Saari-Nordhaus R, Anderson JM (1992) J Chromatogr A 602:127-133. doi:10.1016/ 0021-9673(92)80072-3

3. Yan D, Schwedt G (1990) J Chromatogr A 516:383-393. doi:10.1016/S0021-9673 (01) $89279-7$

4. Li R, Lee WL, Takeuchi T (2007) Talanta 72:1625-1629. doi:10.1016/j.talanta.2007. 03.017

5. Chen ZL, Megharaj M, Naidu R (2007) Talanta 72: 1842-1846. doi:10.1016/j. talanta.2007.02.014

6. Bruzzoniti MC, De Carlo RM, Fungi M (2008) J Sep Sci 31:3182-3189. doi:10.1002/ jssc. 200800319

7. Yoshkawa KJ, Okamura M, Inokuchi M, Akio S (2007) Talanta 72:305-309. doi: 10.1016/j.talanta.2006.10.020

8. Walford SN (2002) J Chromatogr A 956:187-199. doi:10.1016/S0021-9673(02) 00395-3

9. Yan Z, Guo YY, Ye ML, James FS (2005) J Chromatogr A 1085:143-146. doi:10.1016/j.chroma.2004.12.042

10. Valentin-Blasini L, Blount BC, Delinsky A (2007) J Chromatogr A 1155:40-46. doi:10.1016/j.chroma.2007.04.014

11. Sarzanini C(2002) J Chromatogr A 956:3-13. doi:10.1016/S0021-9673(02)00147-4

12. Bruzzoniti MC, De Carlo RD, Fiorilli S, Onida B, Sarzanini C (2009) J Chromatogr A 1216:5540-5547. doi:10.1016/j. chroma.2009.05.052

13. Matsushita S, Tada Y, Baba N, Osako K (1983) J Chromatogr 259:459-464. doi: 10.1016/S0021-9673(01)88034-1

14. Vydac HPLC columns and separation materials. The separation groups, Hesperia, 1990-1991, pp. 20-23

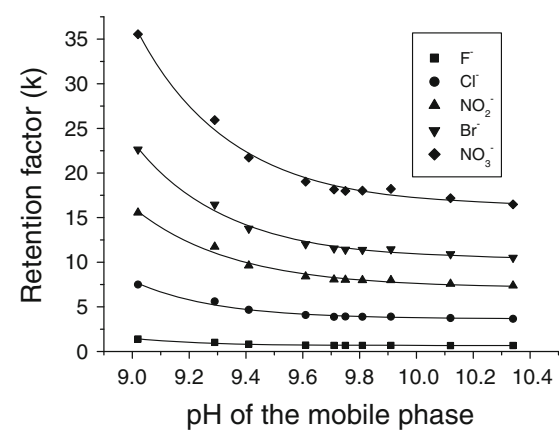

Fig. 4. Changes of the retention factor $\left(k^{\prime}\right)$ with the $\mathrm{pH}$ of the eluent

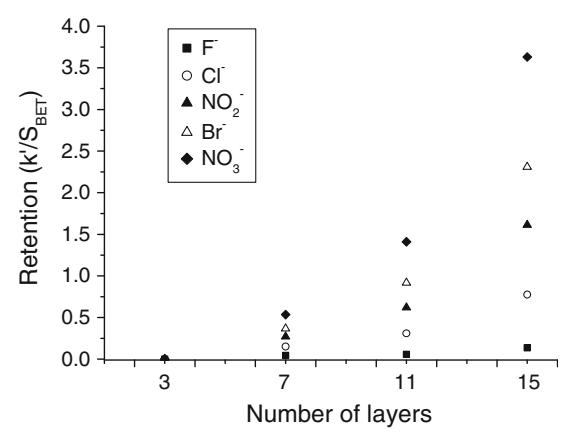

Fig. 5. Changes of the retention factor $\left(k^{\prime}\right)$ with number of bonded layers
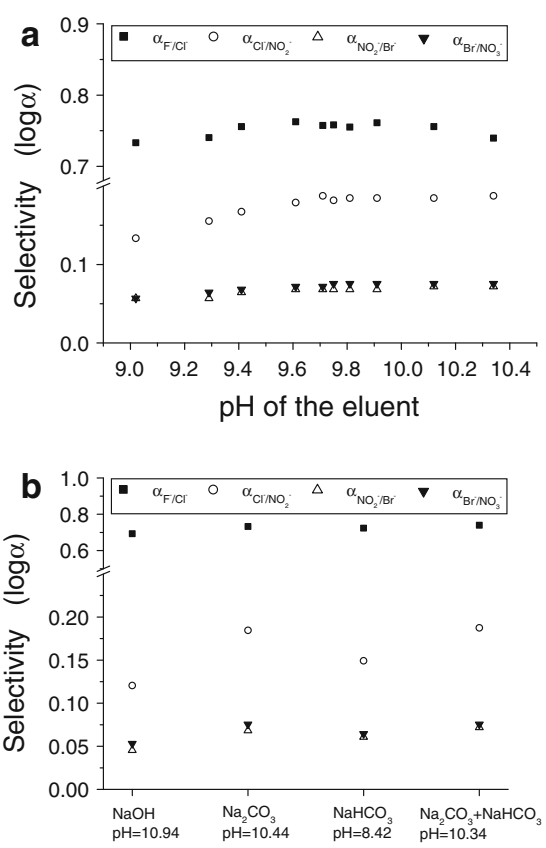

Fig. 6. Changes of the selectivity $\left(\log _{\alpha}\right)$ versus $\mathrm{pH}$ of mobile phase (a) and different eluents (b)

15. Weiss J, Jensen D (2003) Anal Bioanal Chem 375:81-98. doi:10.1007/s00216-0021646-7 
16. Gawdzik B, Matynia T, Osypiuk J (1998) Chromatographia 47:509-514. doi:10.1007/ BF02467487

17. Weiss J (2004) Handbook of Ion Chromatography 3rd ed, VCH, Weinheim
18. Haddad PR, Nesterenko PN, Buchberger W (2008) J Chromatogr A 1184:456-473. doi:10.1016/j.chroma.2007.10.022

19. Hill DJ, O'Donnell JH, Pomery PJ, Whittaker MR (1995) Polym Gels Netw 3:85-97. doi:10.1016/0966-7822(94)00024-2
20. Creed JT, Magnuson ML, Pfaff JD, Brockhoff C (1996) J Chromatogr A 753:261-267. doi:10.1016/S0021-9673(96)00560-2 